\title{
Heat transfer and heating rate of food stuffs in commercial shop ovens
}

\author{
P NAVANEETHAKRISHNAN*, P S S SRINIVASAN and \\ S DHANDAPANI
}

Department of Mechanical Engineering, Kongu Engineering College, Perundurai 638052

e-mail:pnkmech@gmail.com,pnkmech@yahoo.co.in

MS received 24 May 2006; revised 2 November 2006

\begin{abstract}
The CFD analysis of flow and temperature distribution in heating ovens used in bakery shop, to keep the foodstuffs warm, is attempted using finite element technique. The oven is modelled as a two-dimensional steady state natural convection heat transfer problem. Effects of heater location and total heat input on temperature uniformity of foodstuffs are studied. Placing the heater at the bottom of the oven improves the air circulation rate by 17 times and 10 times than that at the top and side of the oven. But the top location provides better uniformity in foodstuff temperature than the other cases. Side location is not preferable. In the present ovens, the heating elements are located at the top. The analysis shows that if heaters are located at the bottom along with additional flow guidance arrangements, energy efficient oven configuration can be obtained.
\end{abstract}

Keywords. Heating oven; finite element analysis; energy efficiency; design improvement.

\section{Introduction}

Technological advancements and improved standards of living have increased the per capita energy use and the associated pollution to an alarming level. A survey carried out on 13 most industrialized nations has shown that about $38 \%$ of the total energy is spent for comfort applications (Liddament \& Orme 1998). Chen (2001) strongly points out that similar aspects will be repeated in the developing nations and meeting such exponentially growing energy demand in the developing nations will be a major task among others in this $21^{\text {st }}$ century. In India, the domestic sector energy consumption is $15 \%$ of the total energy consumption during 1993. During the five-year period (1993-98), the average electricity consumption has grown by $48 \%$, while the domestic sector section consumption raised by $92 \%$, mainly because of comfort applications. Thus, energy needs to be conserved wherever possible.

Computational fluid dynamics (CFD) is a simulation tool that uses powerful computers and applied mathematics to model fluid flow situations for the prediction of heat, mass and

*Corresponding author 
momentum transfer and design optimization, mainly in industrial processes. It is only in recent years that CFD has been applied in the food processing industry (Da-Wen Sun \& Bin Xia 2002). Researchers, equipment designers and process engineers are increasingly using CFD to analyse the flow and performance of process equipment, such as baking ovens, refrigerated display cabinets, stirred tanks, spray dryers, heat exchangers and similar equipment.

Drying is a common manufacturing process and CFD has been applied to drying of fruits (Mathioulakis et al 1998), and spray driers (Langrih \& Fletcher 2001). CFD has been used to study both temperature distribution and flow pattern of food in the sterilization process so as to optimize the quality of food products. Attempts have been made in thermal sterilization (Datta \& Teixeira 1987, Akterian \& Fikiin 1994, Abdul Ghania et al 2001), canned food sterilization (Abdul Ghania et al 1999) using CFD. In food processing, mixing is one of the most common operations. Application of CFD in mixing has been demonstrated (Sahu et al 1999, Rousseaux et al 2001). Consumption of refrigerated and frozen foods has increased continually over the years because such foodstuffs have demonstrated food quality and safety record. CFD has been considerably used in such applications (Hu and Da Wen Sun 2000, Davey \& Pham 2000, Stribling et al 1997 and Shyam et al 2002).

In India, most of the commercial bakeries use electrical heating oven to keep the foodstuffs warm at a specified temperature. The survey by the authors revealed that in most ovens the heating elements are located at the top of the oven with a fan in few models. The present paper makes an attempt to study the effect of heater location in order to improve the design for possible energy conservation and better quality of foodstuffs.

\section{Problem formulation}

Electrically heated ovens are mainly used in bakery (retail) shops in order to keep the foodstuffs warm. These ovens are of different sizes with three heating elements located at the top of the oven. Total input power ratings are in the range of 500 to $1000 \mathrm{~W}$. Some of the ovens use an additional fan of $250 \mathrm{~W}$ rating for hot air circulation. Most commonly used oven has an outer size of $0.7 \mathrm{~m}$ width, $1.2 \mathrm{~m}$ depth and $1.2 \mathrm{~m}$ hight, with three heating coils at three positions, which is taken for the present analysis. As a preliminary study, the problem is modelled and solved as a two-dimensional one as shown in figure 1. Food items (12 numbers) are arranged

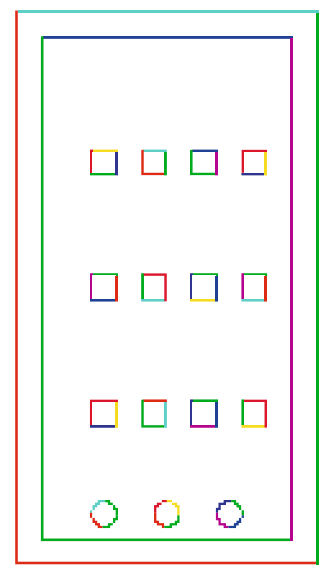

Figure 1. Geometry of oven. 
in three rows and four columns, as shown in figure 1. The clearance between the foodstuffs and the walls is $225 \mathrm{~mm}$ on top and bottom, $100 \mathrm{~mm}$ on the left and $50 \mathrm{~mm}$ on the right. The foodstuffs are of $50 \mathrm{~mm}$ by $50 \mathrm{~mm}$ size. The spacing between the foodstuffs is $200 \mathrm{~mm}$ in the vertical direction and $50 \mathrm{~mm}$ in the horizontal direction.

\subsection{Computational domain}

The computational domain includes the insulated wall (Glass wool, $k=0.075 \mathrm{~W} / \mathrm{m} \mathrm{K}$, three heating elements (Nickel Steel, $5 \mathrm{~mm}$ diameter, $k=380 \mathrm{~W} / \mathrm{mK}$ ), foodstuffs $(k=0.2 \mathrm{~W} / \mathrm{mK}$, for most of the food items, the thermal conductivity range over $0.09-0.5 \mathrm{~W} / \mathrm{mK}$ ) and the enclosed air region. The walls are normally made of sheet metal containing glass insulation ( $10 \mathrm{~mm}$ thick on each side). As the sheet metal thickness is about $0.5 \mathrm{~mm}$ and is of high thermal conductivity $(k=50-150 \mathrm{~W} / \mathrm{mK})$, it will offer negligible resistance to the heat flow. Hence, the sheet metal portion is neglected while modelling.

\subsection{Governing equations}

Steady state, natural convection heat transfer environment is assumed. All the fluid (air) properties are assumed to be constant except density, which is assumed to vary as $\rho=\rho_{\text {ref }}+C_{1}\left(T-T_{\text {ref }}\right)+C_{2}\left(T-T_{\text {ref }}\right)^{2} . T_{\text {ref }}$ is kept as $0^{\circ} \mathrm{C}$, the constants $C_{1}$ and $C_{2}$ are evaluated by curve fitting the data over the range $0-300^{\circ} \mathrm{C}$. As the flow is due to natural convection heat transfer, the flow will be laminar. No heat generation is assumed within the computational domain except at the heating coils. Cartesian coordinate system is employed. Gravity $(g)$ is assumed to act vertically downwards. The governing differential equations, viz. the continuity, $x$-momentum, $y$-momentum, and the energy equation are coupled and are solved simultaneously in the fluid region. Steady state heat conduction equation without heat generation is solved for the insulated wall and foodstuff regions and with heat generation in the heating coil regions.

\subsection{Boundary conditions}

No slip boundary condition ( $V x=0, V y=0)$ is assumed on all the solid surfaces that are in contact with the air. Convection is assumed on all the outside surfaces of the insulated wall. The heat transfer coefficient values are $3.0 \mathrm{~W} / \mathrm{m}^{2} \mathrm{~K}$ for the vertical surfaces and $3.5 \mathrm{~W} / \mathrm{m}^{2} \mathrm{~K}$ for the top surface and $1.5 \mathrm{~W} / \mathrm{m}^{2} \mathrm{~K}$ for the bottom surface; these values are calculated using empirical equations available in standard heat transfer text books, assuming natural convection heat transfer between the insulated walls and the surrounding atmosphere. The surrounding atmospheric temperature of $30^{\circ} \mathrm{C}$ is used in all the analysis. Uniform volumetric heat generation is assumed within the heating element. Total input power of 500, 600, 800 and $1000 \mathrm{~W}$ are used for the analysis. Volumetric heat generation rate is applied over the heating coil region, which is estimated by dividing the total heat generation rate with total volume of three coils.

\section{Solution technique}

The problem is modelled and solved using ANSYS 9.0 Finite Element Analysis software package. The computational domain is first modelled using the pre-processor module of the ANSYS. Then, it is divided into a convenient number of elements using the meshing option. Finer grids are used near the solid-fluid interface regions as shown in figure 2. Grid 


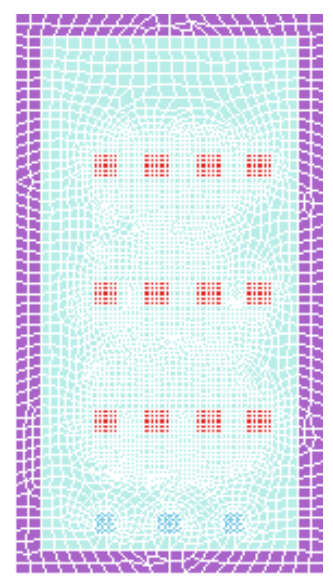

Figure 2. Finite element meshing of the domain.

dependence of the results is verified and grid independence results are reported. The number of elements used is ranged over 35,000 to 50,000 . The boundary conditions are then suitably applied. The properties of air at one atmospheric pressure and $60^{\circ} \mathrm{C}$ are used. The fluid properties $\left(\mu, C_{p}, k\right)$ are assumed as constant except the density where quadratic variation is employed. The steady state form of the governing equations (continuity, momentum and the energy equations) are simultaneously solved. The iterative solution is terminated when the maximum residue falls below $10^{-6}$. The necessary results from the converged solution are extracted using the post-processing option of the software.

\section{Results and discussion}

The oven with 12 foodstuffs and three heating elements are modelled and flow pattern and temperature distribution are analysed. Comparison among the three locations of the heating elements, viz. top, side and bottom of the oven are attempted. Total input power $(Q)$ is varied as $500,600,800$ or $1000 \mathrm{~W}$. In the total 12 cases that are studied, the results of the case with heating elements located at the bottom with $Q=1000 \mathrm{~W}$ are discussed in detail and then the comparisons are made among the three heater locations.

\subsection{Flow and temperature distribution}

The variation of $\mathrm{x}$-component velocity $(\mathrm{Vx})$, y-component velocity $(\mathrm{Vy})$, vector plot of total velocity (Vsum), and stream function within the oven for $Q=1000 \mathrm{~W}$, heating elements located at the bottom are shown in figures 3 to 6 . Variation of temperature $(T)$ is shown in figure $7 \mathrm{f}$. Due to heating, air density decreases. The air with lower density tends to move due to buoyancy and flows through the foodstuffs in the central region of the oven, thus heats the foodstuffs. Once the air reaches the top of the oven, which is relatively at lower temperature, and has higher density, it tends to move down. Thus, at the top region of the oven, air flows towards the side ways and moves down along the gap between the sidewalls (on both sides) and the foodstuffs. Once the air reaches the bottom, which is heated again and the circulation pattern is repeated again and again as shown in figure 5. Thus, the two counter-rotating natural circulation loops are formed which can be clearly observed from the stream function plot shown in figure 6. Certain local circulation is also observed near the right side wall. 

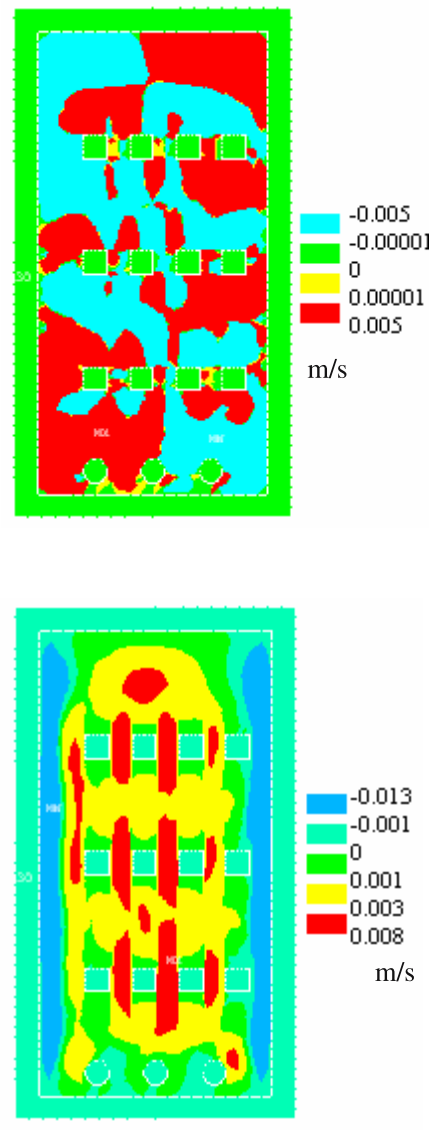

Figure 3. $X$-component velocity distribution (Bottom, $Q=$ $1000 \mathrm{~W})$.

Figure 4. $\quad Y$-component velocity distribution (Bottom, $Q=$ $1000 \mathrm{~W})$.

Horizontal component of air velocity varies from -0.005 to $+0.005 \mathrm{~m} / \mathrm{s}$ as shown in figure 3. The air movement is left to right at the top-right and bottom-left corners and in the opposite way in the other two corners. As the air has to move up in the gap between the foodstuffs in the central region, higher upward velocities, up to $0.008 \mathrm{~m} / \mathrm{s}$, are observed (figure 4).

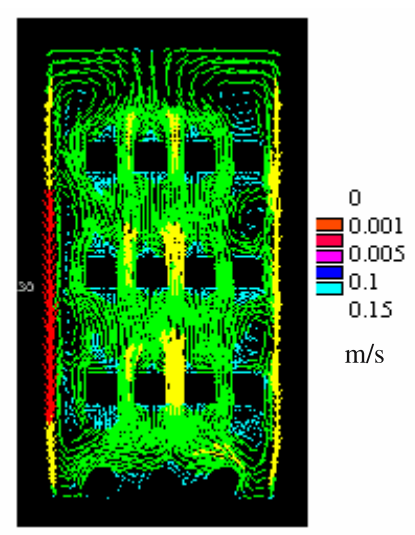

Figure 5. Total velocity distribution (Bottom, $Q=1000 \mathrm{~W}$ ). 


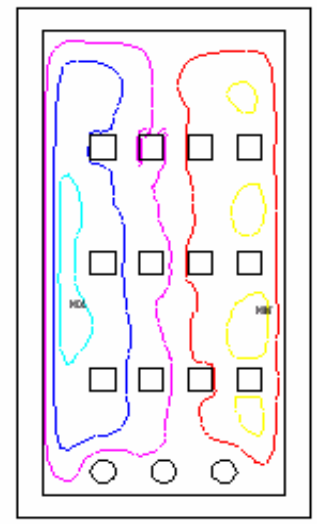

Figure 6. Stream function distribution (Bottom, $Q=1000 \mathrm{~W}$ ).

As all the air went up in the central region returns downwards along both the sidewalls, downward velocities of about $0.013 \mathrm{~m} / \mathrm{s}$ are observed. The temperature plot shown in figure $7 \mathrm{f}$ indicates that nearer to the heating elements, sharp variation in temperature, ranging from 300 to $150^{\circ} \mathrm{C}$ is observed. Along the central region, the temperature ranges over $100-150^{\circ} \mathrm{C}$. In the adjoining regions, the variation is in the range of $75-100^{\circ} \mathrm{C}$ in the top half and $50-75^{\circ} \mathrm{C}$ in the bottom half of the oven.

\subsection{Effect of location of heaters and power input}

For the same heat total input $(Q=1000 \mathrm{~W})$, the effect of heater location on the distribution of total velocity and temperature are shown in figure 7 . The heaters are located at the top (commercial case), at the bottom and at one side (left) of the oven are studied. Figures $7 \mathrm{a}$ to $\mathrm{c}$ show the vector plot of the total velocity for the three heater locations. The maximum velocities observed are lower $(0.0085 \mathrm{~m} / \mathrm{s})$ in case of heater location at top, moderate $(0.015 \mathrm{~m} / \mathrm{s})$, and relatively larger $(0.15 \mathrm{~m} / \mathrm{s})$. Thus, the heater location at top provides about 17 times and 10 times better circulation than the top and side heater locations. In case of top location, the temperatures, in the zones where the foodstuffs are kept, varies in the range of $50-100^{\circ} \mathrm{C}$. The side location of the heater results in larger temperature non-uniformity $\left(50-175^{\circ} \mathrm{C}\right)$ in the foodstuff region. The heater location at the bottom provides moderate non-uniformity $\left(75-150^{\circ} \mathrm{C}\right)$ in the foodstuff region.

Temperature at the middle of foodstuffs obtained for the various heater locations, for the total input power of $1000 \mathrm{~W}$, are plotted in figures 8 to 10 . For almost all the cases analysed, the variation of temperature between the middle and the surfaces of foodstuffs are within $2{ }^{\circ} \mathrm{C}$. In case of bottom location, the bottom row experiences the higher temperature and the temperature drops from bottom row to top row. As the natural circulation is more effective, the foodstuffs at the central region have higher temperature than that at the sides. In case of side location of the heater, temperatures of foodstuffs near the heater are significantly larger than the other regions which are not desirable. For top location, the temperatures of foodstuffs at the top row are larger and decrease from the top to the bottom. For the given heat input, the temperatures of foodstuffs are about 2 times higher in the case of bottom heater location than the top location. Hence, with the lower heat inputs, the desired temperature of foodstuffs can be achieved in the case of bottom location of heaters, thus, resulting in energy savings. But, from temperature uniformity point of view, top location is better than the bottom location for 


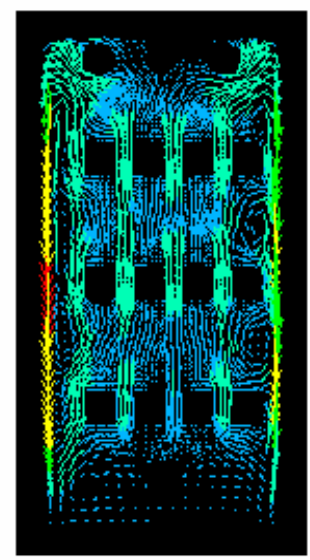

(a)

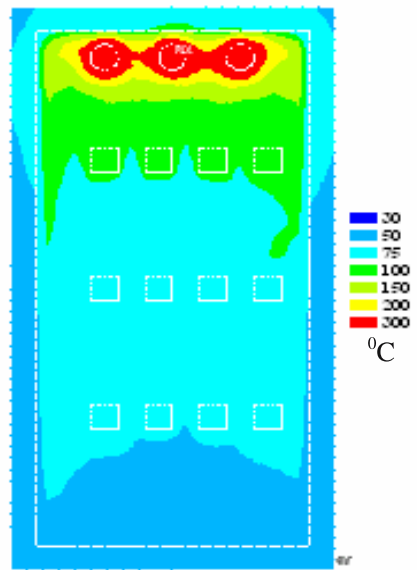

(d)

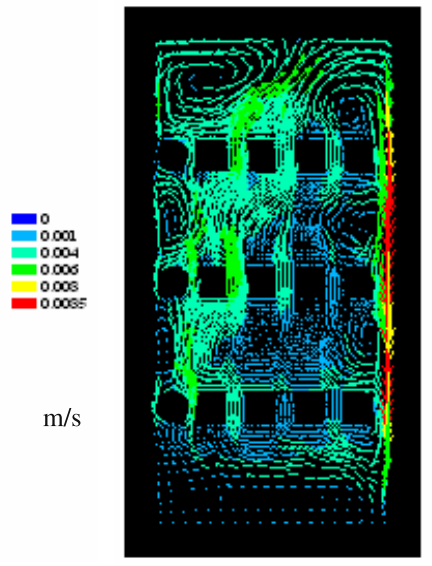

(b)

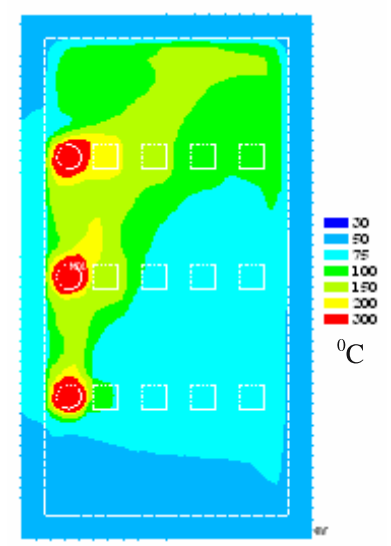

(e)

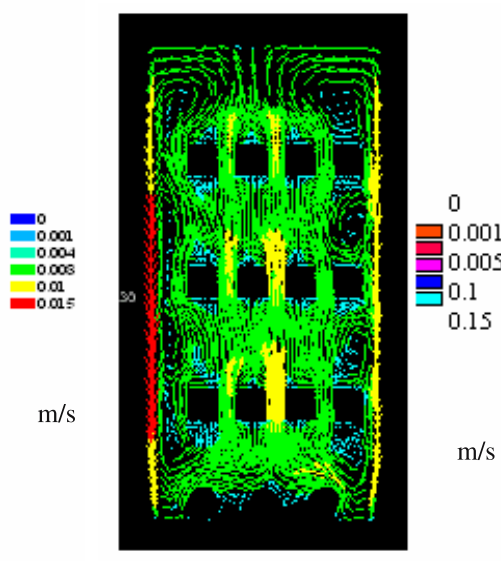

(c)

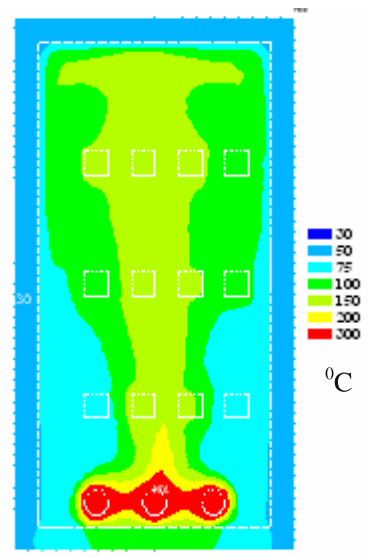

(f)

Figure 7. Velocity distribution Vsum (Top, $Q=1000 \mathrm{~W}$ ) (a), (Side, $Q=1000 \mathrm{~W}$ ) (b), (Bottom, $Q=1000 \mathrm{~W}$ ) (c); Temperature distribution (Top, $Q=1000 \mathrm{~W}$ ) (d), (Top, $Q=1000 \mathrm{~W}$ ) (e), (Top, $Q=1000 \mathrm{~W})(\mathbf{f})$.

the arrangements investigated. Thus, it appears that by incorporating additional flow guiding arrangements, it may be possible to obtain better temperature uniformity in the case of bottom location of heaters, but with a lower heat input than the top location of heaters, which is under further investigation.

$$
\begin{array}{ll}
\multicolumn{2}{c}{\text { Location of foodstuffs }} \\
9-12 & \text { Top row (Row 3) } \\
5-8 & \text { Middle row (Row 2) } \\
1-4 & \text { Bottom row (Row 1) } \\
& (1-4 ; \text { Left to right) }
\end{array}
$$

The total input power $(Q)$ to the heaters in all the three cases is varied as $500,600,800$ and $1000 \mathrm{~W}$. The temperature plots (not shown) revealed that the corresponding foodstuff 

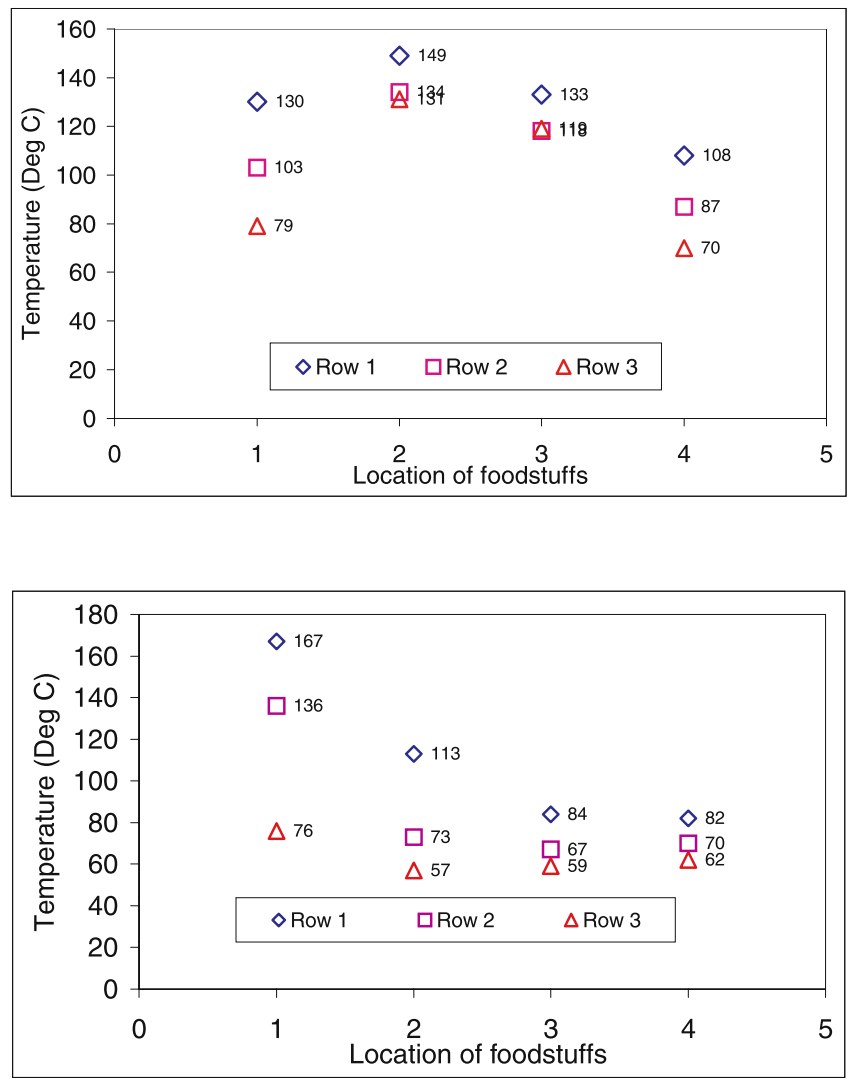

Figure 8. Temperature of foodstuffs with coil at bottom position for $Q=1000 \mathrm{~W}$.
Figure 9. Temperature of foodstuffs with coil at side position for $Q=1000 \mathrm{~W}$.

temperatures varied within $2^{\circ} \mathrm{C}$, when the total input power is increased from 500 to $1000 \mathrm{~W}$. Thus, the steady-state analysis does not show the effect of the heat input. However, lower total heat input may take larger time for the foodstuffs to attain the steady-state. Hence, transient analysis would reveal more while studying the effect of the heat input.

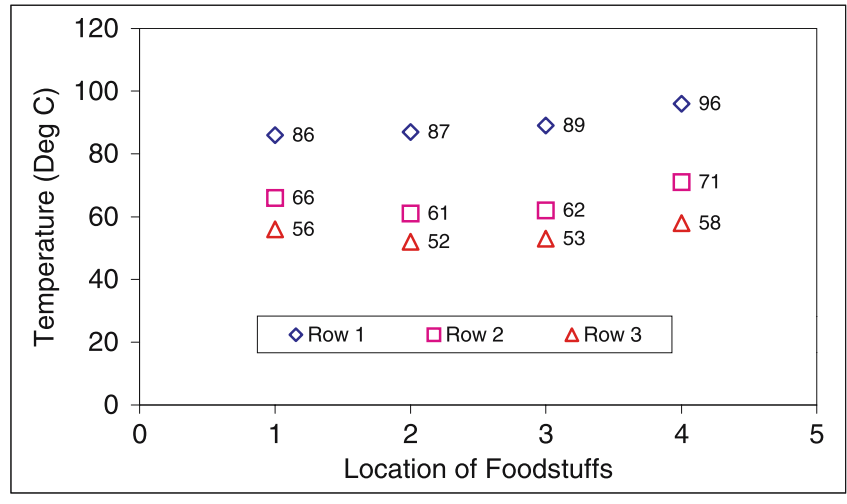

Figure 10. Temperature of foodstuffs with coil at top position for $Q=1000 \mathrm{~W}$. 


\section{Conclusion}

Design improvement for energy conservation is the field of intense research. In this direction, temperature and flow distribution in a commercial foodstuff heating oven is investigated using finite element analysis. The system is modelled as a two-dimensional steady state natural convection heat transfer one. Commercial ovens have the heating elements at the top region inside the oven. In addition to the existing location, bottom and side location of the heaters are also investigated. The following conclusions are arrived at:

(i) Placing the heater at the bottom of the oven improves the air circulation rate by 17 times and 10 times than that at the top and side location.

(ii) Top location provides better uniformity in foodstuff temperature than the other cases.

(iii) Side location is not preferable.

(iv) For the given total heat input, the bottom location results in almost two time's higher temperature of foodstuffs than that of top location.

(v) Bottom heater location with additional flow guides may result in energy efficient oven configuration.

(vi) Transient studies are necessary to understand the effect of heat input.

\section{Nomenclature}

$\begin{array}{ll}\rho & \text { Density of the fluid }\left(\mathrm{kg} / \mathrm{m}^{3}\right) \\ \mu & \text { Dynamic viscosity }(\mathrm{Pa}-\mathrm{S}) \\ C p & \text { Specific heat }(\mathrm{kJ} / \mathrm{kg} \mathrm{K}) \\ g & \text { Acceleration due to gravity }\left(\mathrm{m}^{2} / s\right) \\ h & \text { Convective film co-efficient }\left(\mathrm{W} / \mathrm{m}^{2} \mathrm{~K}\right) \\ k & \text { Thermal conductivity }(\mathrm{W} / \mathrm{m} \mathrm{K}) \\ Q & \text { Total input power to heaters }(\mathrm{W}) \\ V_{x} & \text { Velocity in the x-direction }(\mathrm{m} / \mathrm{s}) \\ V_{y} & \text { Velocity in the y-direction }(\mathrm{m} / \mathrm{s}) \\ V_{\text {sum }} & \text { Total Velocity }(\mathrm{m} / \mathrm{s}) \\ T & \text { Temperature }(\mathrm{K})\end{array}$

\section{References}

Abdul Ghania A G, Farid M M, Chen X D, Richards P 1999 Numerical simulation of natural convection heating of canned food by computational fluid dynamics. J. Food Eng. 41: 55-64

Abdul Ghania A G, Farid M M, Chen X D, Richards P 2001 Thermal sterlisation of canned food in a 3-D pouch using computational fluid dynamics. J. Food Eng. 48: 147-156

Akterian S G, Fikiin K A 1994 Numerical simulation of unsteady heat conduction in arbitrary shaped canned foods during sterilization processes. J. Food Eng. 21: 343-354

Chen N Y 2001 Energy in the $21^{\text {st }}$ Century, Chemical Innovation 15-20

Da-Wen Sun, Bin Xia 2002 Applications of computational fluid dynamics (CFD) in the food industry: a review. Comput. and electronics in Agriculture 34: 5-24

Datta A K, Teixeira A A 1987 Numerical modelling of natural convection heating in canned liquid foods. Trans. ASAE 30: 1542-1551

Davey L M, Pham Q T 2000 A multi-layered two-dimensional finite element model to calculate dynamic product heat load and weight loss during beef chilling. Int. J. Refrigeration 23: 444-456 
Hu Z, Da-Wen Sun 2000 Simulation of heat and mass transfer for vacuum cooling of cooked meats by using computational fluid dynamics code, Presented at the $8^{\text {th }}$ Inter. Cong. Eng. and food, Paper No. O-130, (Mexico: Puebla)

Langrih T A G, Fletcher D F 2001 Spray drying of food ingredients and application of CFD in spray drying. Chem. Eng. and Process. 40: 345-354

Liddament M W, Orme M 1998 Energy saving and ventilation. Applied Thermal Engineering 18: 1101-1109

Mathioulakis E, Karathanos V T, Belessiotis V G 1998 Simulation of air movement in a dryer by computational fluid dynamics: application for the drying of fruits. J. Food Eng. 36: 183-200

Rousseaux J M, Vial C, Muhr H, Plasari E 2001 CFD simulation of precipitation in the sliding-surface mixing device. Chem. Eng. Sci. 56: 1677-1685

Sahu A K, Kumar P, Patwardhan A W, Joshi J B 1999 CFD modelling and mixing in stirred tanks. Chem. Eng. Sci. 54: 285-2293

Shyam S Sablani, Oon-Doo Baik, Michele Marcotte 2002 Neural networks for predicting thermal conductivity of bakery products. J. Food Eng. 52: 299-304

Stribling D, Eng B, Tassou S A, Marriott D Two-dimensional CFD model of a refrigerated display case. ASHRAE Transactions 103: 88-94 